\title{
Co-circulation and co-infections of all dengue virus serotypes in Hyderabad, India 2014
}

\author{
K. VADDADI ${ }^{1}$, C. GANDIKOTA ${ }^{1}$, P. K. JAIN ${ }^{1}$, V. S. V. PRASAD ${ }^{2}$ AND \\ M. VENKATARAMANA ${ }^{1 *}$ \\ ${ }^{1}$ Department of Biotechnology and Bioinformatics, School of Life Sciences, University of Hyderabad, \\ Hyderabad, Telangana State, India \\ ${ }^{2}$ Lotus Children's hospital, Lakdikapul, Hyderabad, Telangana State, India
}

Received 3 December 2016; Final revision 9 May 2017; Accepted 19 June 2017;

first published online 20 July 2017

\section{SUMMARY}

The burden of dengue virus infections increased globally during recent years. Though India is considered as dengue hyper-endemic country, limited data are available on disease epidemiology. The present study includes molecular characterization of dengue virus strains occurred in Hyderabad, India, during the year 2014. A total of 120 febrile cases were recruited for this study, which includes only children and 41 were serologically confirmed for dengue positive infections using non-structural (NS1) and/or IgG/IgM ELISA tests. RT-PCR, nucleotide sequencing and evolutionary analyses were carried out to identify the circulating serotypes/genotypes. The data indicated a high percent of severe dengue $(63 \%)$ in primary infections. Simultaneous circulation of all four serotypes and co-infections were observed for the first time in Hyderabad, India. In total, 15 patients were co-infected with more than one dengue serotype and $12(80 \%)$ of them had severe dengue. One of the striking findings of the present study is the identification of serotype Den-1 as the first report from this region and this strain showed close relatedness to the Thailand 1980 strains but not to any of the strains reported from India until now.

Phylogenetically, all four strains of the present study showed close relatedness to the strains, which are reported to be high virulent.

Key words: Dengue fever (DF), dengue hemorrhagic fever (DHF), dengue shock syndrome (DSS), dengue virus, flaviviruses.

\section{INTRODUCTION}

Dengue is one of the emerging arthropod-borne viral infections in the tropical and subtropical regions of the world. The global epidemiology of mild dengue fever and severe dengue is changing at a very fast rate, which explains the severity of the problem $[1,2]$.

\footnotetext{
* Author for correspondence: M. Venkataramana, Assistant Professor, Department of Biotechnology and Bioinformatics, School of Life Sciences, University of Hyderabad, Hyderabad, Telangana State, India.

(Email: mvrsl@uohyd.ernet.in)
}

Reports indicate that nearly one-third of the world population is at the danger of dengue virus infections and 390 million people are being infected each year. A total of 500000 patients with DHF/DSS are hospitalised every year among whom the larger proportion is from children [3, 4]. Dengue virus belongs to the genus Flavivirus, family Flaviviridae with $11 \mathrm{~kb}$ size positive sense ssRNA as its genome. The genome translates into a single polypeptide, which harbours three structural (capsid (c), precursor membrane (prM), envelope (E)) and seven non-structural (NS) [NS1-NS2A-NS2B-NS3-NS4A-NS4B-NS5] proteins 
by co- and post-translational processes [5]. This virus exists as four closely related but antigenically distinct serotypes (Den 1-4) and each serotype is further resolved into different genotypes [6]. Den-1 serotype consists of five genotypes (I-V), Den-2 has six (Southeast Asian/American, Asian I, Asian II, cosmopolitan, American and Sylvatic), Den-3 has four genotypes (I-IV) and Den-4 serotype has four genotypes (Southeast Asia, Southeast Asia and America, Thailand and Sylvatic) [7]. Each serotype individually or in combination with other serotypes can cause mild dengue fever (DF) to severe dengue hemorrhagic fever (DHF) and dengue shock syndrome (DSS) [8]. Many hypotheses were put forward for the reasons for the severe form of the disease. They are: (i) secondary or tertiary infections, which lead to antibody-dependent enhancement (ADE) mode of virus multiplication, (ii) circulation of multiple serotypes, which leads to co-infections, (iii) change of serotype/genotype in a given geographical region, (iv) change in the genetic material by acquiring nucleotide/amino acid mutations [9-11]. However, the above-listed reasons do not hold true for all cases at all the times. Hence the attempts until now failed to annotate the exact reason for the severe form of the disease despite several lines of research in this direction.

Dengue virus incidences were recorded from India since 1950s and recent reports indicate that India accounts for a third of the global dengue virus infections [3]. All four serotypes were reported to be circulating during different epidemics individually or together, which makes India as one of the hyperendemic countries in the world [12-15]. Continuous replacement of existing serotypes was observed in the last two decades in the country [16-20]. The literature indicates that the southern part of India is the hub of many viral diseases of which the dengue virus occupies the top of the list. Although South Indian states like Telangana and Andhra Pradesh experiences frequent dengue outbreaks with increased disease severity, very limited data are available about circulating serotypes, their complete genetic characteristics and the cause behind disease severity. Reports indicate that several dengue patients from this geographical region expressed very unusual and rare symptoms [21]. Dengue is the leading cause of hospitalisation and death among children in the world including India $[22,23]$. Although children are known to be more susceptible to infectious diseases, very limited information is documented with reference to the dengue virus infections in the children [24-26]. The present study involved samples only from children, collected from the hospital located in Hyderabad, one of the high populated cities of South India. Hyderabad is also known as the centre for other diseases like chikungunya, malaria, tuberculosis and swine flu [27, 28]. Very recent reports also indicated the emergence of poliovirus, which leads to the declaration of the emergency in this city (https://in.news.yahoo.com/ emergency-declared-polio-virus-resurfaces 084800880 . html). Considering the above information, we have given an attempt in the present study to analyse the dengue virus strains occurring in this area and tried to elucidate the reasons behind the severe dengue occurring in children.

\section{METHODS}

\section{Sample collection}

The samples were collected during July-December 2014 from Lotus children's hospital, Hyderabad. Out of the total patients who came to the hospital for the treatment during this period, 120 cases with febrile illness and with high probability of dengue infections were included in the study (WHO, 2009). The consent form was obtained from parents/guardians for the children of age below 7 years. Due to ill cooperation of children age 7-12 years, the consent was also obtained from their parents/guardians. Blood samples were drawn from the patients within 4 days of illness and serological tests were performed by hospital authorities using Pan bio Dengue early detection kit to detect NS1 antigen and $\mathrm{IgG} / \mathrm{IgM}$ capture ELISA test to detect anti-dengue antibodies. Out of 120 cases, 41 were found to be dengue positive alone and were used for further analysis. The excluded samples were dengue negative or positive along with other infections. The confirmed patients were categorised into primary and secondary infections based on the IgG and IgM levels. Clinical profiles of the patients were documented and the cases were classified into Dengue without warning signs and severe forms like Dengue with warning signs and severe dengue as per the WHO/TDR 2009 guidelines [29].

\section{Viral RNA extraction and reverse transcription PCR}

Viral RNA was extracted from the infected serum samples using QIAamp viral RNA mini kit (Qiagen) as per the manufacturer's instructions. Above obtained viral RNA was reverse transcribed to cDNA using 
AMV reverse transcriptase (Promega) and further amplified by Q5 high fidelity DNA polymerase (NEB). The above obtained amplified product was used as a template for serotyping using serotype specific primers [30].

For genotyping analysis, the extracted RNA was reverse transcribed using gene specific primers by Superscript ${ }^{\mathrm{TM}}$ III first-strand synthesis system (Invitrogen). Q5 high fidelity DNA polymerase (NEB) was used for further amplification. Amplified genes for genotyping of Den-1, 2 and 4 were complete envelope regions (1485 bp) and for Den-3 was partial CprM (281 bp) sequence. Full-length envelope sequences from two different samples for Den-1, one sample for each Den-2\&4 and partial CprM sequences from two different samples for Den-3 were used.

\section{Cloning and sequencing}

The above obtained amplified products were cloned using InsTA Cloning kit (Thermo scientific) and the inserts were sequenced thrice by a commercial sequencing company (Scigenome, Cochin, Kerala). The above sequences were deposited in GenBank and obtained the accession numbers (KU551904, KU551905, KX379688, KU551907, KT282375 and KX343906).

\section{Phylogenetic and sequence analyses}

Sequences were aligned and compared with published sequences available in NCBI database using Clustal $\mathrm{W}$ of Mega 6.0 [31]. Phylogenetic trees were constructed using the maximum-likelihood method based on General Time Reversible model with gamma distribution and invariant sites. Bootstrap values were generated by constructing 1000 replicates. The aligned nucleotide and amino acid sequences were analysed by using Bio-Edit $6 \cdot 0 \cdot 7$ software. In order to analyse the differences at the amino acid sequence level, we have carried out amino acid sequence comparison between the sequences of the strains of the present study and the strains reported earlier.

\section{RESULTS}

\section{Samples and their clinical manifestations}

Among the 41 samples, 38 (92\%) were of primary infections as determined by $\operatorname{IgG} / \operatorname{IgM}$ levels. A total of $15(36 \%)$ samples were classified as Dengue without warning signs and $26(64 \%)$ as severe disease (23
$(56 \%)$ Dengue with warning signs and three $(7 \cdot 3 \%)$ Severe Dengue). In total 30 patients had thrombocytopenia disregarding the disease severity. Besides the usual symptoms like fever, rash, vomiting, some of the unusual rare manifestations like pleural effusion, elevated liver enzymes (ALT/AST), organ impairment, mucosal bleeding, septic shock particularly in Dengue with warning signs/ Severe Dengue patients were also observed (Table 1).

\section{Serotype analysis}

Serotyping was performed using 33 dengue positive serum samples and the serotype-specific size of the obtained amplified product for Den-1 was $482 \mathrm{bp}$, Den-2 was 119 bp, Den-3 was 290 bp and for Den-4 it was 392 bp (Supplementary fig. S1A). Co-infections were observed in 15 samples $(45 \cdot 4 \%)$ with different serotype combinations (Supplementary fig. S1B). Out of 18 single serotype infections, dengue 1 was identified in six patients $(33.3 \%)$, dengue 2 in five $(27 \cdot 7 \%)$, dengue 3 in three $(16.6 \%)$ and dengue 4 in four patients $(22 \cdot 2 \%)$. Among the co-infections, $1 \& 2$ serotype combination was dominant with seven (46.6\%), followed by $2 \& 4$ in five $(33 \cdot 3 \%), 3 \& 4$ in two $(13 \cdot 3 \%)$ and $1 \& 3$ in one patient $(6 \cdot 6 \%)$. Considering both single and co-infections, Den-1 infected 14 patients whereas Den-2 infected 17, Den-3 infected six and Den-4 infected 11 patients (Fig. 1). The data also showed that $80 \%(12 / 15)$ of co-infected patients (Table 2) and 38\% (7/18) of single-infected patients were suffered from the severe form of the disease (Dengue with warning signs/ Severe Dengue).

\section{Genotype analysis}

Since the dengue virus has a uniform substitution rate across the structural and NS genes, any of the genomic segments can be used for evolutionary analysis [32, 33]. In this study, Envelope (Den- 1, 2 and 4) and CprM (Den- 3) structural gene sequences were used, which were also known to accumulate adaptive mutations under selective pressure for favouring mosquitomediated transmission and infections [17]. Den-1 strains sequenced in this study (Acc No: KU551904 and KU551905) clustered under Genotype III (Cosmopolitan) along with Thailand and Comoros strains, which suggested that they are different from the earlier reported strains from India (Fig. 2). Earlier reported Indian strains also belonged to the same genotype but branched along with Brunei 
Table 1. Clinical characteristics of patients based on dengue disease severity

\begin{tabular}{|c|c|c|c|}
\hline Clinical features & $\begin{array}{l}\text { Dengue without warning signs } \\
(N=15)\end{array}$ & $\begin{array}{l}\text { Dengue with warning signs } \\
(N=23)\end{array}$ & $\begin{array}{l}\text { Severe dengue } \\
(N=3)\end{array}$ \\
\hline Sex (male/female) & $8 / 7$ & $13 / 10$ & $2 / 1$ \\
\hline Age* & $6(0 \cdot 75-11)$ & $6 \cdot 77(0 \cdot 8-13)$ & $4 \cdot 3(2 \cdot 3-7)$ \\
\hline NS1 positive & 13 & 21 & 3 \\
\hline IgM/IgG positive & $2 / 1$ & $2 / 2$ & $1 / 0$ \\
\hline \multicolumn{4}{|l|}{ Infection type } \\
\hline Primary & 14 & 21 & 3 \\
\hline Secondary & 1 & 2 & 0 \\
\hline Liver enlargement ${ }^{\dagger}$ & 0 & 5 & 0 \\
\hline Pleural effusion ${ }^{\dagger}$ & 1 (mild) & 4 & 2 \\
\hline Abdominal pain & 0 & 11 & 2 \\
\hline Ascites $^{\dagger}$ & 0 & 5 & 1 \\
\hline Mucosal bleeding ${ }^{\dagger}$ & 0 & 2 & 0 \\
\hline Septic shock & 0 & 2 & 3 \\
\hline Thrombocytopenia $^{\dagger}$ & $9(60 \%)$ & $21(91 \%)$ & $3(100 \%)$ \\
\hline Platelets/mL (Thousands) & $195(40-390)$ & $95(8-230)$ & $48(30-71)$ \\
\hline Leukocyte count (cells/cumm) & $5090(1800-9400)$ & $7873(1700-3400)$ & $18933(9600-28300)$ \\
\hline RBC count (milli/cumm) & $4 \cdot 1(3 \cdot 9-4 \cdot 6)$ & $4 \cdot 3(3 \cdot 40-5 \cdot 62)$ & $2 \cdot 6(2 \cdot 1-3 \cdot 1)$ \\
\hline SGOT (IU/L) & $107 \cdot 3(10 \cdot 3-331)$ & $82 \cdot 5(7 \cdot 5-310)$ & $1178.65(187 \cdot 3-217)$ \\
\hline SGPT (IU/L) & $58 \cdot 9(8 \cdot 3-136)$ & $65 \cdot 4(13 \cdot 2-245)$ & $3334.65(669 \cdot 3-6000)$ \\
\hline
\end{tabular}

* Fever, rash, cough, vomiting are common symptoms for all dengue manifestations.

$\dagger$ Abdominal pain, Pleural effusion, Ascites, Mucosal bleeding represents Dengue with warning signs.

¥ Shock, Organ impairment etc., represents Severe dengue.

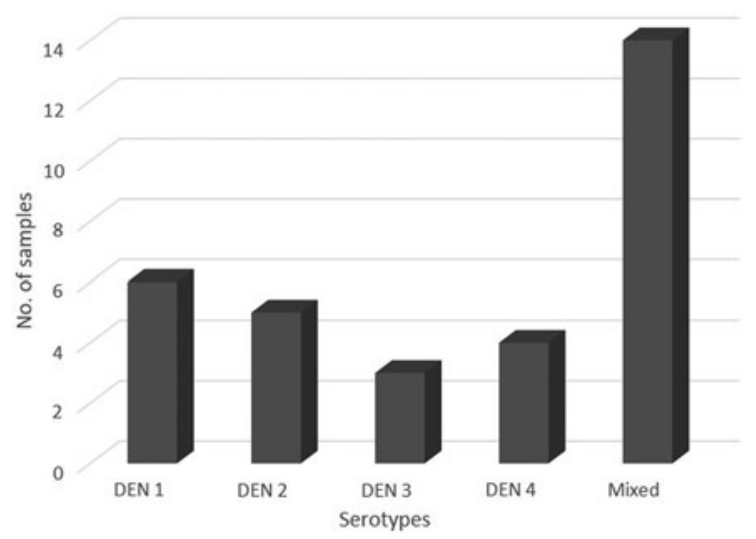

Fig. 1. Distribution of serotypes across the samples.

strains. Nucleotide sequence comparison of complete envelope gene revealed that this isolate is $97 \%$ identical to the Thailand 1980 and Comoros strains, whereas $96 \%$ identical to recently reported Indian strains [RGCB585, 592, 419 and RR57, 107, 121]. In the case of Den-2 (Acc No: KX379688), phylogenetic analysis showed that the present isolate grouped under genotype IV (Cosmopolitan). This strain clustered along with 2009 Indian strain (Hyderabad) and Sri Lankan 1996 strain (Fig. 3). Nucleotide sequence comparison of the complete envelope gene revealed that this isolate is $96 \%$ identical to 2009 strain reported earlier from Hyderabad and other Indian strains (GWL18, RR44 and OD2112).

CprM gene sequences of present Den-3 serotype (Acc No: KU551907 and KT282375) clustered along with previous Indian and China strains branching altogether into a single lineage of genotype III (Fig. 4). Pairwise alignment of these sequences revealed $97-99 \%$ identity with previous Indian isolates. Den-4 strain (Acc No: KX343906) of the present study is grouped into the lineage $\mathrm{C}$ of genotype I which is represented by Indian isolates (Fig. 5). The nucleotide sequence comparison of Den-4 envelope gene revealed that this isolate is $98 \%$ identical to 2009 Indian strain reported from Pune.

\section{Amino acid sequence analysis}

Multiple sequence alignment analysis carried in the present study showed many unique amino acid substitutions. In the case of Den-1 envelope sequence, the unique amino acids were identified at the positions 98 (D-G), 248 (Q-R), 339 (T-I) and 358 (V-A) when compared with the sequences of published strains (Table 3, Supplementary fig. S2). But, $272 \mathrm{M}$ is similar to Thailand strains, whereas in the case of recent 


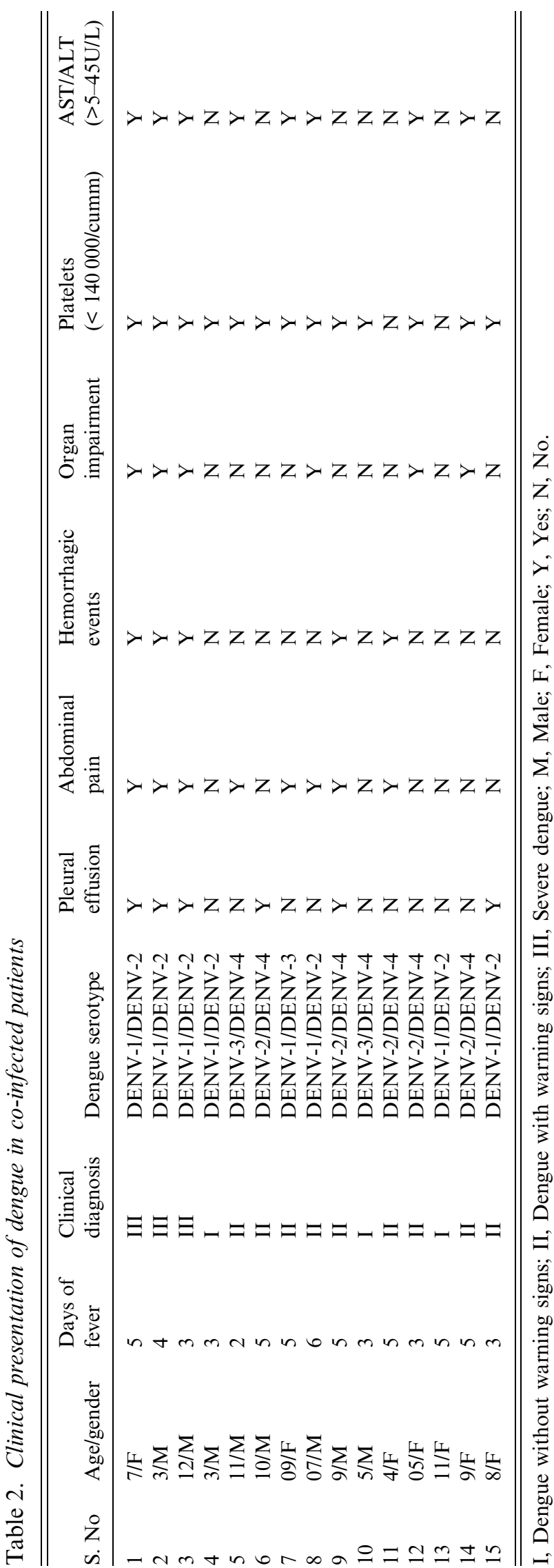

Indian strains it is $272 \mathrm{~T}$. Similarly, 337F of the present strain matches with Thailand, Comoros and South Indian strains whereas in the case of all North Indian strains it is 337I. In case of Den-2, 141I of present strain matches with Sri Lanka 1996 and 2009 Hyderabad strains, whereas in the case of all North Indian strains it is $141 \mathrm{~V}$. A substitution, 162I was found to be present in all strains except 2009 Hyderabad strain (Table 4, Supplementary fig. S3). In case of Den-3, the data showed only one unique mutation 5 (V-A) compared with the reported Den-3 isolates. At position 83 it is $\mathrm{K}$, which is similar to all the reported strains except from Sri Lanka (Table 5, Supplementary fig. S4). In case of Den-4 also one unique mutation was observed at position L429F of the envelope when compared with other strains in the same lineage. $221 \mathrm{~A}$ and $351 \mathrm{~V}$ were found to be similar for both the present strain and Pune strain reported in 2009 (Table 6, Supplementary fig. S5).

\section{DISCUSSION}

Dengue infections were known for ancient times but less attention was given due to less severe illness and self-limiting nature. But, during 1980s the course of these infections was changed and causing significant morbidity and mortality throughout the globe including India. Needless to mention that this kind of effect is more with reference to the children but less number of reports are there due to difficulty in getting children samples alone. Few reports suggest that children are more prone to the severe dengue but with secondary or tertiary infections $[25,26]$. In India also increasing trend of DHF/DSS cases was observed after 1980s, of which the first DHF/DSS report was 1988, in children [24]. In the present study, which was undertaken only on children, the clinical data indicated a high percent $(63 \cdot 3 \%)$ of severe disease (Dengue with warning signs/ Severe Dengue) in primary infections (including two deaths), which is much more than the earlier reports (Table 1). Hence, we have continued our investigations to bring as much as possible clarity on the reason behind the increased number of DHF/DSS cases.

There are few reports indicating the co-circulation of all four serotypes in a single outbreak from India in which the percent of co-infections is less and there is no clarity on disease severity $[13,14]$. In addition, few reports also showed the circulation of all four serotypes over a period of few years during which the co-infections were found to be less [12, 20]. Only one 


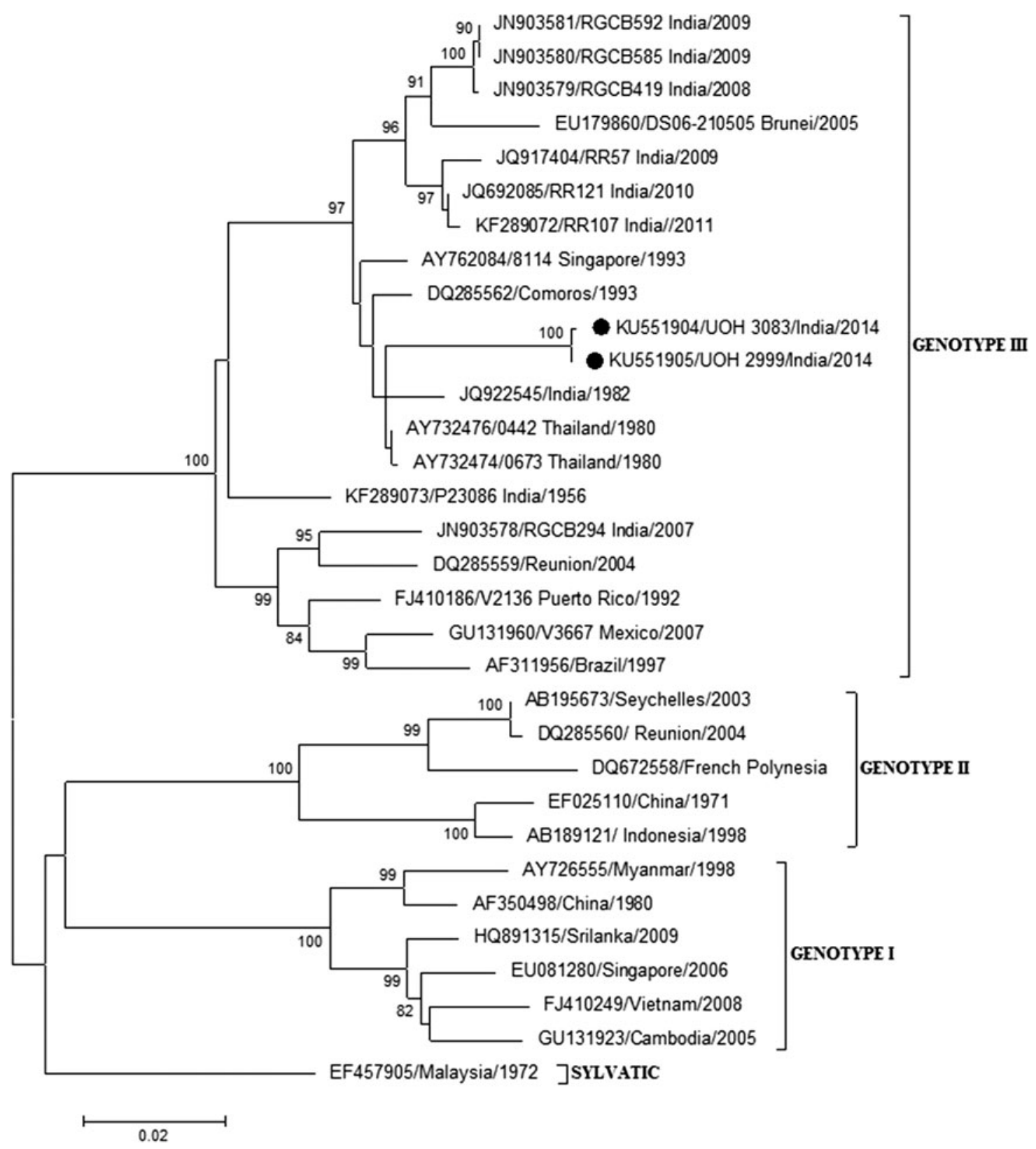

Fig. 2. Phylogenetic tree of Den-1 strains generated by Maximum-Likelihood method based on the complete envelope gene sequence $(1485 \mathrm{bp})$. Bootstrap values more than $70 \%$ are shown. The scale bar represents the number of nucleotide substitutions per site. GenBank accession number, name, place and year of isolation are also indicated. Sequences obtained in the study are shown (filled circles).

of the four serotypes was reported to be dominated in both the above cases. Serotyping analysis of the present study showed the simultaneous circulation of all four serotypes for the first time, in Hyderabad, Southern India. Serotype distribution across the total analysed samples was nearly equal. A recent multicentric study carried out on dengue infections in India including Hyderabad, on seroprevalence in children below 11 years suggested the existence of dengue specific immunoglobulins (IgGs) in 59\% of the studied population and indicated the circulation of all four serotypes [34]. This study supports our present observations carried out at molecular level. The other aspect of the present study is the high percent (45.4\%) of co-infections (Fig. 1). Co-circulation of all serotypes simultaneously provides an opportunity for co-infections [14, 35]. Co-infections reported earlier in India from Delhi were 19\% \& 18.3\% in 2006 and 


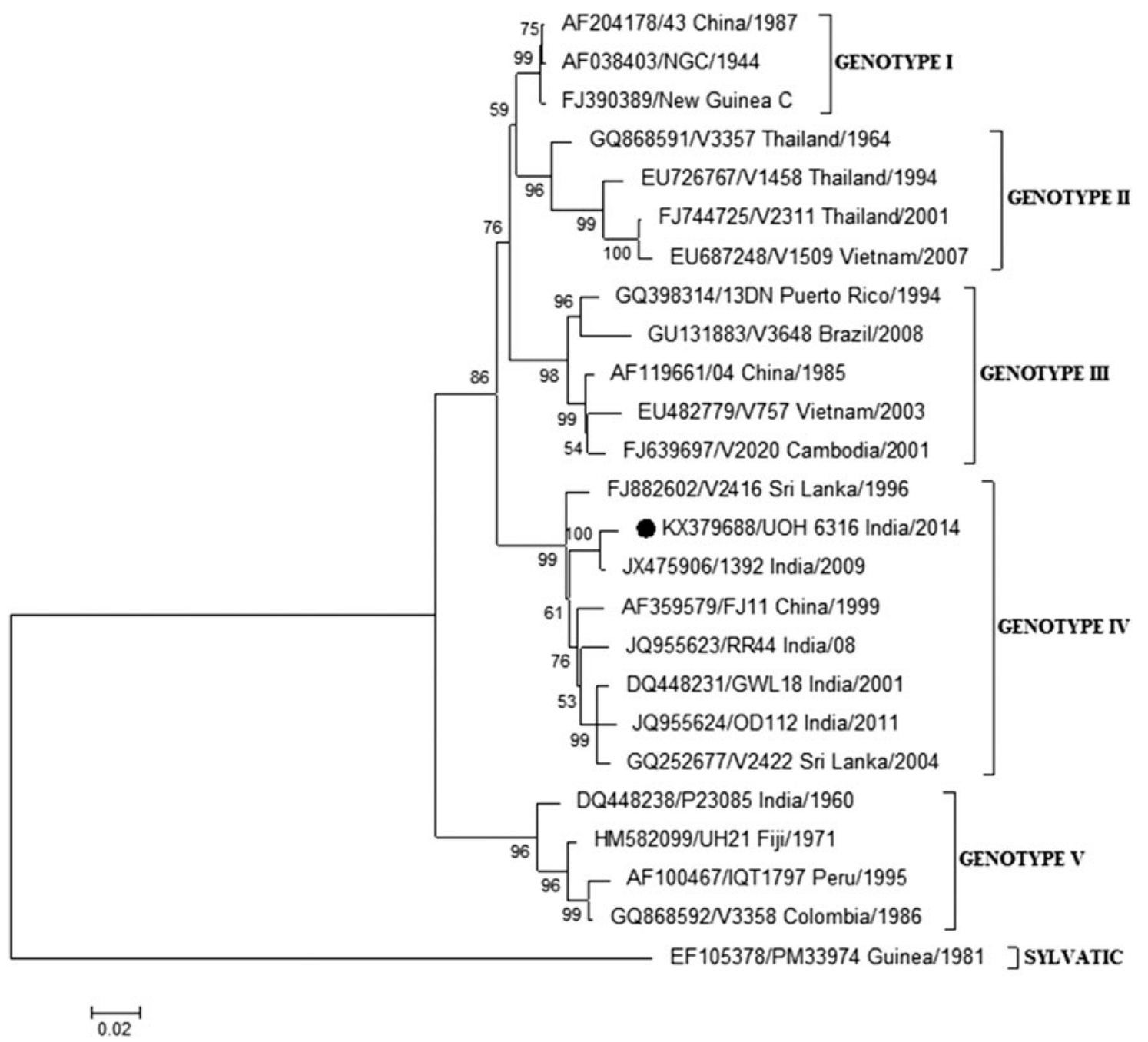

Fig. 3. Phylogenetic tree of Den-2 strains generated by Maximum-Likelihood method based on the complete envelope gene sequence (1485 bp). Bootstrap values more than $70 \%$ are shown. The scale bar represents the number of nucleotide substitutions per site. GenBank accession number, name, place and year of isolation are also indicated. Sequences obtained in the study are shown (filled circle).

during 2011-2014, respectively [16, 36]. In this case, the percent of the distribution of all serotypes is unequal, which leads to the co-infections with participation of restricted serotypes and hence recorded less percent of co-infections. In this direction, another study showed a high percent $(56 \cdot 7 \%)$ of co-infections during the circulation of three serotypes among which one serotype extremely dominated. However, there is no clarity on disease severity in this report [15]. Hence, we speculate that the equal distribution of all serotypes observed in the present study might have brought the situation for increased co-infections with the participation of all serotypes hence to the high percent of severe dengue $(80 \%)$. In Delhi, $66.6 \%(6 / 9)$ of co-infected patients had DHF/DSS [14]. Reports also indicate that the co-infections lead to the high viral load, which would trigger the severe form of the disease [8]. Our observations gains support from both the above two reports. We also speculate that the co-infected dengue virus strains may get an opportunity to undergo inter-serotype recombination, which might lead to the evolution of the new strains with better fitness and virulence.

Data of the present study also indicated the circulation of Den-1, which appears to be the first time in Hyderabad, India; because characterization of Den-1 serotype was not reported from this region, until now. Another major observation is the genetic distinctness of the Den-1 strains from the previously reported strains elsewhere from India (Fig. 2). Phylogenetic tree showed that the strains of the present study are close to the Thailand 1980 strains and 


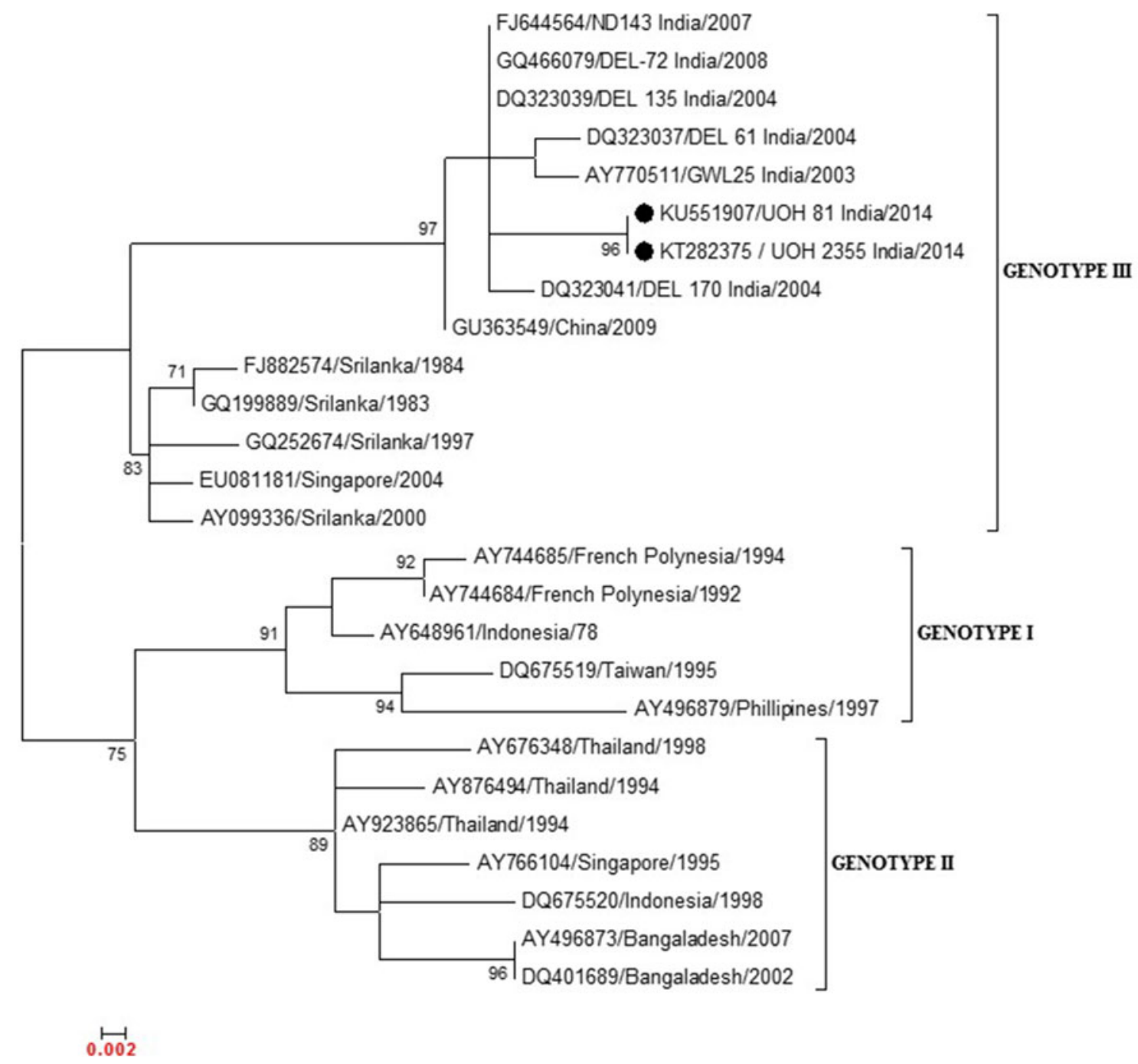

Fig. 4. Phylogenetic tree of Den-3 strains generated by Maximum-Likelihood method based on the partial CprM gene sequences $(281 \mathrm{bp})$. Bootstrap values more than $70 \%$ are shown. The scale bar represents the number of nucleotide substitutions per site. GenBank accession number, name, place and year of isolation are also indicated. Sequences obtained in the study are shown (filled circles).

these strains are known to associate with severe dengue [37]. Evolutionary analysis of Den-2 strains of present study reveals the circulation of genotype IV, which is similar to all the other strains reported from India (Fig. 3). The data also indicated the involvement of Den-2 in many co-infections. This genotype is known to be involved in causing severe dengue [18, 38]. Den-3 strain circulating in this area grouped into genotype III, which is also known to associate with severe dengue [39]. Very less genetic information is available in case of Den-4 from India and the studies carried out during 2011-14 in Delhi also failed to find a single patient with Den-4 [36]. But in our study, Den-4 was detected in $33 \%$ of infected patients and found to be grouped into genotype I C. The results showed its close relatedness to the Den-4 strain characterised from Pune, India, in 2009 with high percent similarity at nucleotide level (Fig. 5). It is important to notice that the present Den-4 strain is associated with severe dengue patient, who had many unusual symptoms such as respiratory distress, pleural effusion and elevated levels of liver enzymes (ALT/AST) similar to the strain from Pune, which also showed its association with DSS with the similar type of symptoms [40]. The relatedness of present strain with Pune strain may be due to the exotic introduction of the virus, as these two urban cities are located $650 \mathrm{~km}$ distance apart with many daily travellers. Den-1 and Den-4 of the present study showed several unique amino acids at different positions of the 


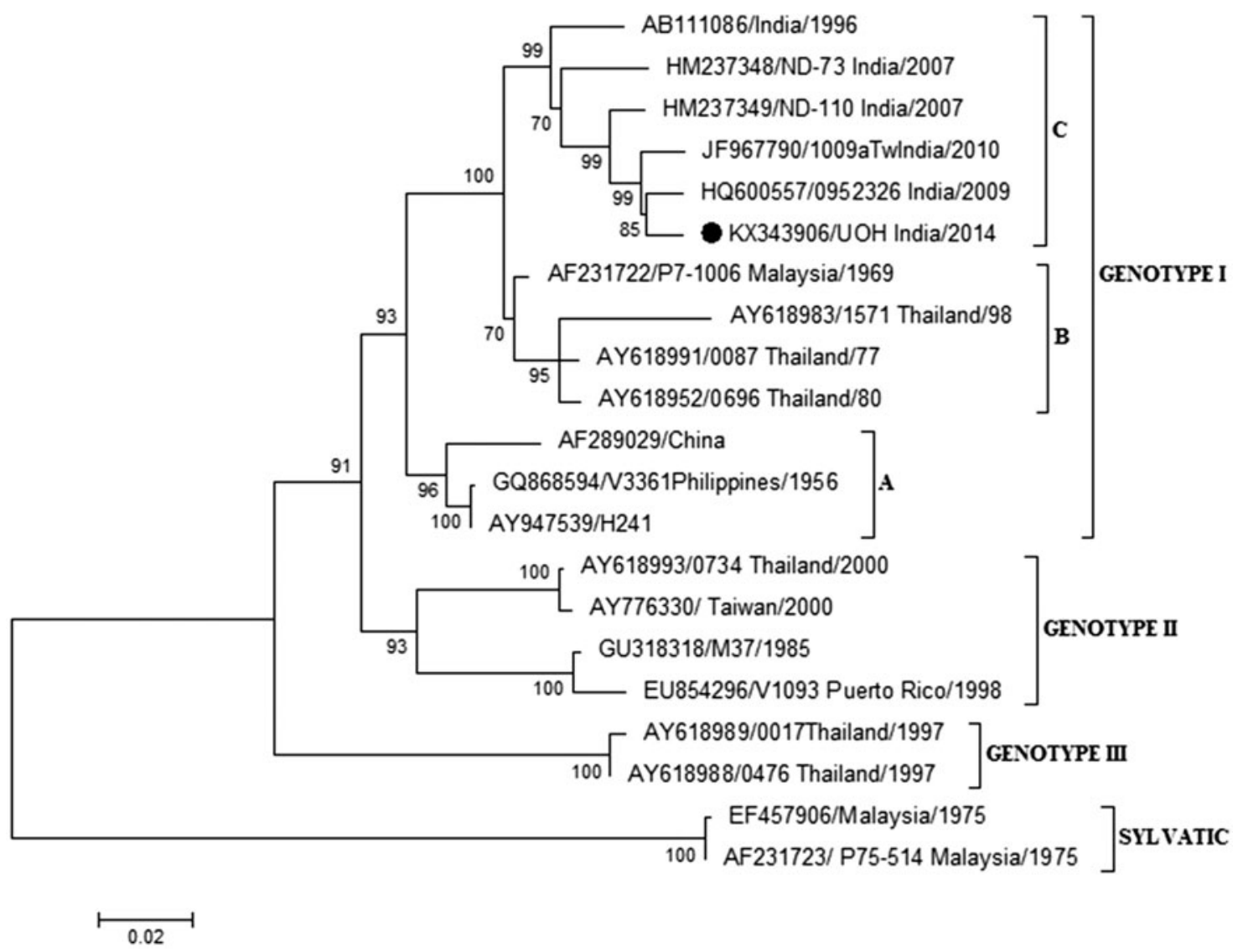

Fig. 5. Phylogenetic tree of Den-4 strains generated by Maximum-Likelihood method based on the complete envelope gene sequence (1485 bp). Bootstrap values more than $70 \%$ are shown. The scale bar represents the number of nucleotide substitutions per site. GenBank accession number, name, place and year of isolation are also indicated. Sequences obtained in the study are shown (filled circle).

Table 3. Unique amino acid substitutions observed in the Hyderabad (UOH) strains and the closely related Den-1 isolates

\begin{tabular}{|c|c|c|c|c|c|c|c|c|c|c|c|c|}
\hline S. no & $\begin{array}{l}\text { Amino } \\
\text { acid } \\
\text { position }\end{array}$ & $\begin{array}{l}\text { Sing } \\
8114 \\
(93)\end{array}$ & $\begin{array}{l}\text { Como } \\
04 \cdot 329 \\
(93)\end{array}$ & $\begin{array}{l}\text { ThD1 } \\
0442 \\
(80)\end{array}$ & $\begin{array}{l}\text { ThD1 } \\
0673 \\
(80)\end{array}$ & $\begin{array}{l}\text { RGCB } \\
419 \\
\text { (IND-08) }\end{array}$ & $\begin{array}{l}\text { RGCB } \\
592 \\
\text { (IND-09) }\end{array}$ & $\begin{array}{l}\text { DRDE } \\
\text { RR57 } \\
\text { (IND-09) }\end{array}$ & $\begin{array}{l}\text { DRDE } \\
\text { RR121 } \\
\text { (IND-10) }\end{array}$ & $\begin{array}{l}\text { DRDE } \\
\text { RR107 } \\
\text { (IND-11) }\end{array}$ & $\begin{array}{l}\text { UOH } \\
3083 \\
\text { (IND-14) }\end{array}$ & $\begin{array}{l}\text { UOH } \\
2999 \\
\text { (IND-14) }\end{array}$ \\
\hline 1 & 98 & D & D & D & D & D & D & D & D & D & G & G \\
\hline 2 & 248 & Q & Q & Q & Q & $\mathrm{Q}$ & $\mathrm{Q}$ & $\mathrm{Q}$ & $\mathrm{Q}$ & $\mathrm{Q}$ & $\mathbf{R}$ & $\mathbf{R}$ \\
\hline 3 & 272 & $\mathrm{~T}$ & $\mathrm{~T}$ & $M$ & $M$ & $\mathrm{~T}$ & $\mathrm{~T}$ & $\mathrm{~T}$ & $\mathrm{~T}$ & $\mathrm{~T}$ & $M$ & $M$ \\
\hline 4 & 297 & $\mathrm{~T}$ & V & $\mathrm{V}$ & V & V & V & V & V & V & V & V \\
\hline 5 & 329 & $\mathrm{~T}$ & $\mathrm{~T}$ & $\mathrm{~T}$ & $\mathrm{~T}$ & $\mathrm{~T}$ & $\mathrm{~T}$ & $\mathrm{~T}$ & $\mathrm{~T}$ & $\mathrm{~T}$ & A & A \\
\hline 6 & 337 & $\mathrm{~F}$ & $\mathrm{~F}$ & F & $\mathrm{F}$ & $\mathrm{F}$ & $\mathrm{F}$ & I & I & I & $\mathrm{F}$ & F \\
\hline 7 & 339 & $\mathrm{~T}$ & $\mathrm{~T}$ & $\mathrm{~T}$ & $\mathrm{~T}$ & $\mathrm{~T}$ & $\mathrm{~T}$ & $\mathrm{~T}$ & $\mathrm{~T}$ & $\mathrm{~T}$ & I & I \\
\hline 8 & 359 & V & V & V & V & V & V & V & V & V & A & A \\
\hline 9 & 380 & V & I & I & I & I & I & I & I & I & I & I \\
\hline 10 & 384 & E & E & $\mathrm{K}$ & E & E & E & E & E & E & E & E \\
\hline 11 & 425 & I & I & M & I & I & I & I & I & I & I & I \\
\hline 12 & 472 & $\mathrm{~S}$ & $\mathrm{~S}$ & $\mathrm{~S}$ & $\mathrm{~S}$ & $\mathrm{~S}$ & $\mathrm{~N}$ & $\mathrm{~S}$ & S & $\mathrm{S}$ & S & $\mathrm{S}$ \\
\hline
\end{tabular}

Unique amino acid substitutions identified in UOH strains are indicated by bold letters and substitutions similar to the Thailand strains are denoted by italics 
Table 4. Unique amino acid substitutions observed in the Hyderabad (UOH) strains and the closely related Den-2 isolates

\begin{tabular}{|c|c|c|c|c|c|c|c|c|c|}
\hline S. no & $\begin{array}{l}\text { Amino } \\
\text { acid position }\end{array}$ & $\begin{array}{l}\text { V2416 } \\
\text { (SRIL-96) }\end{array}$ & $\begin{array}{l}\text { V2422 } \\
\text { (SRIL-04) }\end{array}$ & $\begin{array}{l}\text { FJ11 } \\
\text { (CHIN-99) }\end{array}$ & $\begin{array}{l}\text { GWL18 } \\
\text { (IND-01) }\end{array}$ & $\begin{array}{l}\text { RR44 } \\
\text { (IND-08) }\end{array}$ & $\begin{array}{l}1392 \\
\text { (IND-09) }\end{array}$ & $\begin{array}{l}\text { OD2112 } \\
\text { (IND-09) }\end{array}$ & $\begin{array}{l}\text { UOH } \\
\text { (IND-14) }\end{array}$ \\
\hline 1 & 141 & I & V & V & V & V & I & V & I \\
\hline 2 & 150 & A & A & A & $\mathrm{T}$ & A & A & A & A \\
\hline 3 & 162 & I & I & I & I & I & V & I & I \\
\hline 4 & 322 & I & V & I & V & I & I & V & I \\
\hline 5 & 380 & I & I & I & I & V & I & I & I \\
\hline 6 & 478 & A & $\mathrm{S}$ & $\mathrm{S}$ & $\mathrm{S}$ & $\mathrm{S}$ & $\mathrm{S}$ & $\mathrm{S}$ & $\mathrm{S}$ \\
\hline 7 & 484 & V & V & V & V & I & V & V & V \\
\hline
\end{tabular}

Table 5. Unique amino acid substitutions observed in the Hyderabad (UOH) strains and the closely related Den-3 isolates

\begin{tabular}{llllllllll}
\hline \hline S. no & $\begin{array}{l}\text { Amino } \\
\text { acid position }\end{array}$ & SRIL 83 & $\begin{array}{l}\text { SRIL } \\
2000\end{array}$ & $\begin{array}{l}\text { GWL25 } \\
\text { (IND-03) }\end{array}$ & $\begin{array}{l}\text { ND143 } \\
\text { (IND-07) }\end{array}$ & $\begin{array}{l}\text { DEL72 } \\
\text { (IND-08) }\end{array}$ & $\begin{array}{l}\text { CHINA } \\
\text { (09) }\end{array}$ & $\begin{array}{l}\text { UOH 81 } \\
\text { (INDI-14) }\end{array}$ & $\begin{array}{l}\text { UOH 2355 } \\
\text { (INDI-14) }\end{array}$ \\
\hline 1 & 5 & $\mathrm{~V}$ & $\mathrm{~V}$ & $\mathrm{~V}$ & $\mathrm{~V}$ & $\mathrm{~V}$ & $\mathrm{~V}$ & $\mathrm{~A}$ & $\mathbf{A}$ \\
2 & 83 & $\mathrm{~K}$ & $\mathrm{Q}$ & $\mathrm{K}$ & $\mathrm{K}$ & $\mathrm{K}$ & $\mathrm{K}$ & $\mathrm{K}$ & $\mathrm{K}$ \\
\hline \hline
\end{tabular}

Unique amino acid substitutions identified in UoH strains are indicated by bold letters

Table 6. Unique amino acid substitutions observed in the Hyderabad (UOH) strains and the closely related Den-4 isolates

\begin{tabular}{|c|c|c|c|c|c|c|c|c|}
\hline S. no & $\begin{array}{l}\text { Amino } \\
\text { acid position }\end{array}$ & $\begin{array}{l}0087 \\
\text { (THAI-77) }\end{array}$ & $\begin{array}{l}0696 \\
\text { (THAI-80) }\end{array}$ & (INDI-96) & $\begin{array}{l}\text { ND-73 } \\
\text { (IND-07) }\end{array}$ & $\begin{array}{l}\text { ND-110 } \\
\text { (IND-07) }\end{array}$ & $\begin{array}{l}0952326 \\
\text { (IND-09) }\end{array}$ & $\begin{array}{l}\mathrm{UOH} \\
\text { (IND-14) }\end{array}$ \\
\hline 1 & 122 & $\mathrm{~S}$ & $\mathrm{~S}$ & $\mathrm{~S}$ & $\mathrm{~S}$ & $\mathrm{~S}$ & $\mathrm{~T}$ & $\mathrm{~S}$ \\
\hline 2 & 130 & $\mathrm{~V}$ & $\mathrm{~V}$ & $\mathrm{~V}$ & V & I & I & I \\
\hline 3 & 132 & I & I & I & V & I & I & I \\
\hline 4 & 174 & $\mathrm{~K}$ & $\mathrm{~K}$ & $\mathrm{~K}$ & $\mathrm{~K}$ & $\mathrm{E}$ & E & $\mathrm{E}$ \\
\hline 5 & 202 & $\mathrm{~K}$ & $\mathrm{~K}$ & $\mathrm{~K}$ & $\mathrm{~K}$ & $\mathrm{~N}$ & $\mathrm{~N}$ & $\mathrm{~N}$ \\
\hline 6 & 206 & W & W & W & W & $\mathrm{R}$ & W & W \\
\hline 7 & 210 & $\mathrm{~K}$ & $\mathrm{~K}$ & $\mathrm{~K}$ & $\mathrm{~K}$ & $\mathrm{R}$ & $\mathrm{K}$ & $\mathrm{K}$ \\
\hline 8 & 221 & $\mathrm{~T}$ & $\mathrm{~T}$ & $\mathrm{~T}$ & $\mathrm{~T}$ & $\mathrm{~T}$ & $\mathbf{A}$ & $\mathbf{A}$ \\
\hline 9 & 265 & $\mathrm{~T}$ & $\mathrm{~T}$ & $\mathrm{~T}$ & A & $\mathrm{T}$ & $\mathrm{T}$ & $\mathrm{T}$ \\
\hline 10 & 271 & $\mathrm{D}$ & $\mathrm{D}$ & $\mathrm{D}$ & $\mathrm{D}$ & $\mathrm{D}$ & Y & D \\
\hline 11 & 277 & $\mathrm{H}$ & $\mathrm{H}$ & $\mathrm{H}$ & $\mathrm{H}$ & $\mathrm{H}$ & $\mathrm{L}$ & $\mathrm{H}$ \\
\hline 12 & 329 & A & A & A & V & A & A & A \\
\hline 13 & 351 & I & I & V & I & I & V & $\mathbf{V}$ \\
\hline 14 & 366 & $\mathrm{~N}$ & $\mathrm{~N}$ & $\mathrm{~N}$ & $\mathrm{~S}$ & $\mathrm{~N}$ & $\mathrm{~N}$ & $\mathrm{~N}$ \\
\hline 15 & 393 & $\mathrm{R}$ & $\mathrm{R}$ & $\mathrm{R}$ & $\mathrm{R}$ & $\mathrm{R}$ & $\mathrm{T}$ & $\mathrm{R}$ \\
\hline 16 & 429 & $\mathrm{~L}$ & $\mathrm{~L}$ & $\mathrm{~L}$ & $\mathrm{~L}$ & $\mathrm{~L}$ & $\mathrm{~L}$ & $F$ \\
\hline
\end{tabular}

$\overline{\text { Amino acid substitutions similar to IND-09 strain are denoted by bold letters and unique amino acid substitution identified in }}$ UoH strain is indicated by italics.

sequenced gene segments (Tables 3, 6). This kind of amino acid changes may be due to the positive selection, which might have imparted to the severe form of the dengue. In addition to that, few amino acids are similar to the strains, which are reported to be associated with severe dengue (Table 3). However, further investigations are required to elucidate the role of changed amino acids. Overall, the data showed that Den- 1 is a new report, Den- $2 \& 3$ were existing and Den- 4 is the replaced version, during 2014 in Hyderabad, India.

In summary, the clinical data indicated the high percent of severe dengue during primary infections 
in children in Hyderabad, India. Further analysis showed the simultaneous circulation of all four serotypes for the first time, which indicated the Hyper-endemicity of dengue infections in this geographical region. The data also showed co-infections (also high percent) for the first time in Hyderabad during the year 2014. Another novelty of the present study is the occurrence of serotype Den-1, which seems to be the first report from this geographical area. Strains of all four serotypes dealt in the present study showed close relatedness to the strains, which caused severe dengue elsewhere in the world. So, co-circulation, co-infections and high virulent strains of all dengue virus serotypes together brought a unique situation, which contributed for enhanced DHF/DSS in children in this geographical area. Since the samples used for serotyping in this study were obtained from children's hospital, a recruiting bias cannot be excluded. However, we felt that the observations of this study would give the alarm with reference to the dynamics of dengue infections in this geographical region as well as other dengue-prone regions of the world.

\section{SUPPLEMENTARY MATERIAL}

The supplementary material for this article can be found at https://doi.org/10.1017/S0950268817001479

\section{ACKNOWLEDGMENTS}

The authors expressed the acknowledgments to the University Grants Commission (UGC; 41-518/2012 (SR)), India, UPE 1\&2 (UH/LS/UPE-2/28/2015), University of Hyderabad, for the financial support. K.V. gets a fellowship from UGC and both C.G. \& P.K.J. gets from DBT, India.

\section{ETHICS STATEMENT}

The present study was reviewed and approved by the Institutional Ethics Committee, University of Hyderabad, Hyderabad, India (UH/IEC/2014/24\&25).

\section{DECLARATION OF INTEREST}

Authors declared that there is no conflict of interests.

\section{REFERENCES}

1. Gubler DJ. Dengue and dengue hemorrhagic fever. Clinical Microbiology Reviews 1998; 3: 480-496.
2. Chakravarti A, et al. Improved detection of dengue virus serotypes from serum samples-evaluation of single-tube multiplex RT-PCR with cell culture. Dengue Bulletin 2006; 30: 133-140.

3. Bhatt S, et al. The global distribution and burden of dengue. Nature 2013; 496: 504-507.

4. WHO. Dengue and Severe Dengue. Fact sheet no. 117, July 2016 (http://www.who.int/mediacentre/factsheets/ fs117/en/index.html). Accessed August 2016.

5. Leopoldo GG, Claudia VF and Andrea VG. Functional RNA elements in the dengue virus genome. Viruses 2011; 3: 1739-1756.

6. Holmes EC, Twiddy SS. The origin, emergence and evolutionary genetics of dengue virus. Infection Genetics and Evolution 2003; 3: 19-28.

7. Scott CW and Nikos V. Molecular evolution of dengue viruses: contributions of phylogenetics to understanding the history and epidemiology of the preeminent arboviral disease. Infection Genetics and Evolution 2009; 9: 523-540.

8. Thomas L, et al. Influence of the dengue serotype, previous dengue infection, and plasma viral load on clinical presentation and outcome during a dengue- 2 and dengue-4 co-epidemic. The American Journal of Tropical Medicine and Hygiene 2008; 78: 990-998.

9. Holmes EC and Burch SS. The causes and consequences of genetic variation in dengue virus. Trends in Microbiology 2000; 8: 74-77.

10. Martins VdoC, et al. Clinical and virological descriptive study in the 2011 outbreak of dengue in the Amazonas, Brazil. PLoS ONE 2014; 9: e100535.

11. Shrivastava A, et al. Lineage shift of dengue virus in Eastern India: an increased implication for DHF/DSS. Epidemiology and Infection 2015; 143: 1599-1605.

12. Gupta $\mathbf{E}$ and Neha B. Current perspectives on the spread of dengue in India. Infection and Drug Resistance 2014; 7: $337-342$.

13. Gupta N, et al. Chaturvedi. dengue in India. Indian Journal of Medical Research 2012; 136: 373-390.

14. Bharaj P, et al. Concurrent infections by all four dengue virus serotypes during an outbreak of dengue in 2006 in Delhi, India. Virology Journal 2008; 5: 1.

15. Anoop M, et al. Genetic characterization of dengue virus serotypes causing concurrent infection in an outbreak in Ernakulam, Kerala, South India. Indian Journal of Experimental Biology 2010; 48: 849-857.

16. Dar L, et al. The first major outbreak of dengue hemorrhagic fever in Delhi, India. Emerging Infectious Diseases 1999; 5: 589-590.

17. Anoop M, et al. Complete genome sequencing and evolutionary analysis of dengue virus serotype 1 isolates from an outbreak in Kerala, South India. Virus Genes 2012; 45: 1-13.

18. Dash PK, et al. Complete genome sequencing and evolutionary analysis of Indian isolates of dengue virus type 2. Biochemical and Biophysical Research Communications 2013; 436: 478-485.

19. Anoop M, et al. Lineage shift in Indian strains of dengue virus serotype-3 (Genotype III), evidenced by detection of lineage IV strains in clinical cases from Kerala. Virology Journal 2013; 10: 37. 
20. Dash PK, et al. Emergence of dengue virus type 4 (genotype I) in India. Epidemiology and Infection 2011; 139: 857-861.

21. Neeraja M, et al. Unusual and rare manifestations of dengue during a dengue outbreak in a tertiary care hospital in South India. Archives of Virology 2014; 159: 1567-1573.

22. WHO. Variable endemicity for DF/DHF in countries of SEA region. SEARO2016. (http://www.searo.who.int/ entity/vector_borne_tropical_diseases/data/data_factsheet/en/).

23. Branco MR, et al. Risk factors associated with death in Brazilian children with severe dengue: a case-control study. Clinics 2014; 69: 55-60.

24. Kabra SK, et al. Dengue hemorrhagic fever in children in Delhi. Bulletin of the World Health Organization 1992; 70: 105-108.

25. Hammond SN, et al. Differences in dengue severity in infants, children, and adults in a 3-year hospital-based study in Nicaragua. The American Journal of Tropical Medicine and Hygiene 2005; 73: 1063-1070.

26. Lam PK, et al. Clinical characteristics of dengue shock syndrome in vietnamese children: a 10-year prospective study in a single hospital. Clinical Infectious Diseases 2013; 57: 1577-1586.

27. Satheesh G, Prabhu NP, Venkataramana M. 3D Modeling of dengue virus NS4B and Chikungunya virus nsP4: identification of a common drug target and designing a single antiviral inhibitor. Current Computer-Aided Drug Design 2014; 10: 361-373.

28. Venkataramana M, Vaibhav V, Anand KK. Emergence of swine flu in Andhra Pradesh: facts and future. Indian Journal of Microbiology 2009; 49: 320-323.

29. WHO. Dengue Guidelines for Diagnosis, Treatment, Prevention and Control, New edn. Geneva, 2009 WHO/HTM/NTD/DEN/2009· 1 .

30. Lanciotti RS, et al. Rapid detection and typing of dengue viruses from clinical samples by using reverse transcriptase-polymerase chain reaction. Journal of Clinical Microbiology 1992; 30: 545-551.

31. Tamura K, et al. MEGA6: molecular evolutionary genetics analysis version 6.0. Molecular Biology and Evolution 2013; 30: 2725-2729.

32. Klungthong $\mathbf{C}$, et al. Molecular genotyping of dengue viruses by phylogenetic analysis of the sequences of individual genes. Journal of Virological Methods 2008; 154: 175-181.

33. Domingo C, et al. Use of a short fragment of the C-terminal $\mathrm{E}$ gene for detection and characterization of two new lineages of dengue virus 1 in India. Journal of Clinical Microbiology 2006; 44: 1519-1529.

34. Garg S, et al. Dengue serotype-specific seroprevalence among 5- to 10-year-old children in India: a community-based cross-sectional study. International Journal of Infectious Diseases 2017; 54: 25-30.

35. Loroño-Pino MA, et al. Common occurrence of concurrent infections by multiple dengue virus serotypes. The American Journal of Tropical Medicine and Hygiene 1999; 61: 725-730.

36. Afreen $\mathbf{N}$, et al. Phylogenetic and molecular clock analysis of dengue serotype 1 and 3 from New Delhi, India. PLOS ONE 2015; 10: e0141628.

37. Tang Y, et al. Comparative analysis of full-length genomic sequences of 10 dengue serotype 1 viruses associated with different genotypes, epidemics, and disease severity isolated in Thailand over 22 Years. The American Journal of Tropical Medicine and Hygiene 2010; 83: 1156-1165.

38. Leitmeyer KC, et al. Dengue virus structural differences that correlate with pathogenesis. Journal of Virology 1999; 73: 4738-4747.

39. Dash PK, et al. Reemergence of dengue virus type-3 (subtype-III) in India: implications for increased incidence of DHF \& DSS. Virology Journal 2006; 3: 55.

40. Cecilia D, et al. Detection of dengue-4 virus in Pune, western India after an absence of 30 years - its association with two severe cases. Virology Journal 2011; 8: 46. 